\title{
VARIABILITY OF MANUAL AND COMPUTERIZED METHODS FOR MEASURING CORONAL VERTEBRAL INCLINATION IN COMPUTED TOMOGRAPHY IMAGES
}

\author{
Tomaž VRtovec $\bowtie$, Franjo Pernuš And Boštuan LiKar
}

University of Ljubljana, Faculty of Electrical Engineering, Tržaška cesta 25, SI-1000 Ljubljana, Slovenia e-mail: tomaz.vrtovec@fe.uni-lj.si, franjo.pernus@fe.uni-lj.si, bostjan.likar@fe.uni-lj.si

(Received May 14, 2015; accepted June 11, 2015)

\begin{abstract}
Objective measurement of coronal vertebral inclination (CVI) is of significant importance for evaluating spinal deformities in the coronal plane. The purpose of this study is to systematically analyze and compare manual and computerized measurements of CVI in cross-sectional and volumetric computed tomography (CT) images. Three observers independently measured CVI in 14 CT images of normal and 14 CT images of scoliotic vertebrae by using six manual and two computerized measurements. Manual measurements were obtained in coronal cross-sections by manually identifying the vertebral body corners, which served to measure CVI according to the superior and inferior tangents, left and right tangents, and mid-endplate and mid-wall lines. Computerized measurements were obtained in two dimensions (2D) and in three dimensions (3D) by manually initializing an automated method in vertebral centroids and then searching for the planes of maximal symmetry of vertebral anatomical structures. The mid-endplate lines were the most reproducible and reliable manual measurements (intra- and inter-observer variability of $0.7^{\circ}$ and $1.2^{\circ}$ standard deviation, $\mathrm{SD}$, respectively). The computerized measurements in 3D were more reproducible and reliable (intra- and inter-observer variability of $0.5^{\circ}$ and $0.7^{\circ} \mathrm{SD}$, respectively), but were most consistent with the mid-wall lines $\left(2.0^{\circ} \mathrm{SD}\right.$ and $1.4^{\circ}$ mean absolute difference). The manual CVI measurements based on mid-endplate lines and the computerized CVI measurements in 3D resulted in the lowest intra-observer and inter-observer variability, however, computerized CVI measurements reduce observer interaction.
\end{abstract}

Keywords: computed tomography, computerized measurements, coronal vertebral inclination, manual measurements, measurement variability.

\section{INTRODUCTION}

The evaluation of spinal deformities from medical images is essential for diagnosis and treatment of pathological conditions affecting the spine. Scoliosis, which can be observed as a deviation of the spinal curve from the straight line in the coronal (frontal) plane, is one of the most frequent manifestations of spinal deformities. Accurate and objective measurement of coronal vertebral inclination (CVI) is therefore of significant importance, and the angle of inclination between the superior and inferior vertebral endplates in coronal radiographs, i.e., the Cobb angle (Cobb, 1948), is the most established measurement technique. However, such measurements are biased by observer interpretation, anatomical deformations of vertebrae and image acquisition (Capasso et al., 1992), as radiographs represent a two-dimensional (2D) projection of the observed anatomy. With the development of modern three-dimensional (3D) imaging techniques, it is possible to measure CVI from 2D cross-sectional images extracted from 3D volumes, as well as from original 3D volumetric images, which better display the 3D nature of spinal deformities. To the best of our knowledge, a systematic analysis of CVI measurements from 3D images has not been performed yet. The purpose of this study is to systematically evaluate the reproducibility and reliability of segmental CVI measurements from computed tomography (CT) images.

\section{MATERIALS AND METHODS}

\section{IMAGES}

Fourteen vertebrae from one normal CT spine image (male subject, 47 years, Cobb angle around $1^{\circ}$ between $\mathrm{T} 5$ and T12) and 14 vertebrae from one scoliotic CT spine image (female subject, 36 years, Cobb angle around $60^{\circ}$ between T5 and T12, right thoracic curve), both including levels between $\mathrm{T} 1$ and L2, were included in this study. The images were acquired by the Tomoscan AVE and MX 8000 CT scanners (Philips Medical Systems, The Netherlands) for diagnostic purposes not related to this study, and the institution of origin anonymized the images before handing them over. 

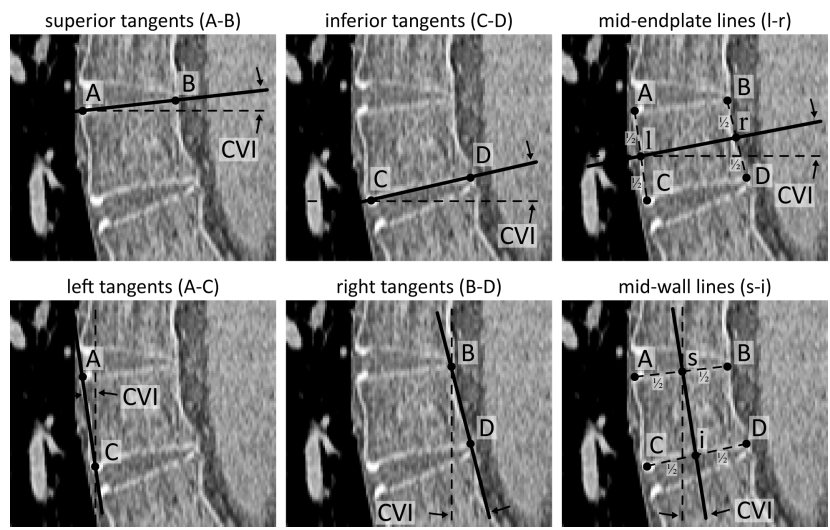

Fig. 1. Manual coronal vertebral inclination (CVI) measurements in two-dimensional (2D) oblique coronal cross-sections.

\section{OBSERVERS}

Manual and computerized measurements were performed by three observers (observer 1: a postgraduate biomedical engineering student; observer 2: a medical imaging researcher; observer 3: a spine surgeon) with different experience in medical imaging and orthopedic surgery, who were familiar with basic tools for visualization of spine and vertebrae, and encountered spine and vertebrae images on daily basis either for research, software development, treatment planning or evaluation purposes. Each observer independently performed a set of measurements twice, leaving a two-week period between the first and second set of measurements, resulting in six sets of measurements for each vertebra.

\section{MANUAL CVI MEASUREMENTS}

For the purpose of manual measurement of CVI, we developed a dedicated computer program that guided each observer step-by-step through the measurement procedure. For each vertebra, the observers first manually identified the vertebral centroid in 3D and estimated the axial and sagittal vertebral tilt, which served to automatically extract the oblique 2D coronal cross-section from the CT image. Oblique cross-sections were used instead of orthogonal to obtain the best possible coronal views and therefore reducing measurement errors that may be introduced by axial and sagittal vertebral tilt. In the oblique coronal cross-section, the observers manually identified the four vertebral body corners, which were used to evaluate CVI according to six different measurements (Fig. 1). The superior tangents and the inferior tangents represent the segmental Cobb angle (Cobb, 1948) at the superior and inferior vertebral endplate, respectively. The left tangents and the right tangents describe the inclination of the left and right vertebral body wall, respectively. The mid-endplate lines are defined between the central points of the left and right vertebral body wall, while the mid-wall lines are defined between the central points of the superior and inferior vertebral endplate. The angles of CVI were computed from the inclinations of the obtained lines against horizontal or vertical references. The average time required to perform manual measurements for one vertebra by each observer was estimated to around $4 \mathrm{~min}$.

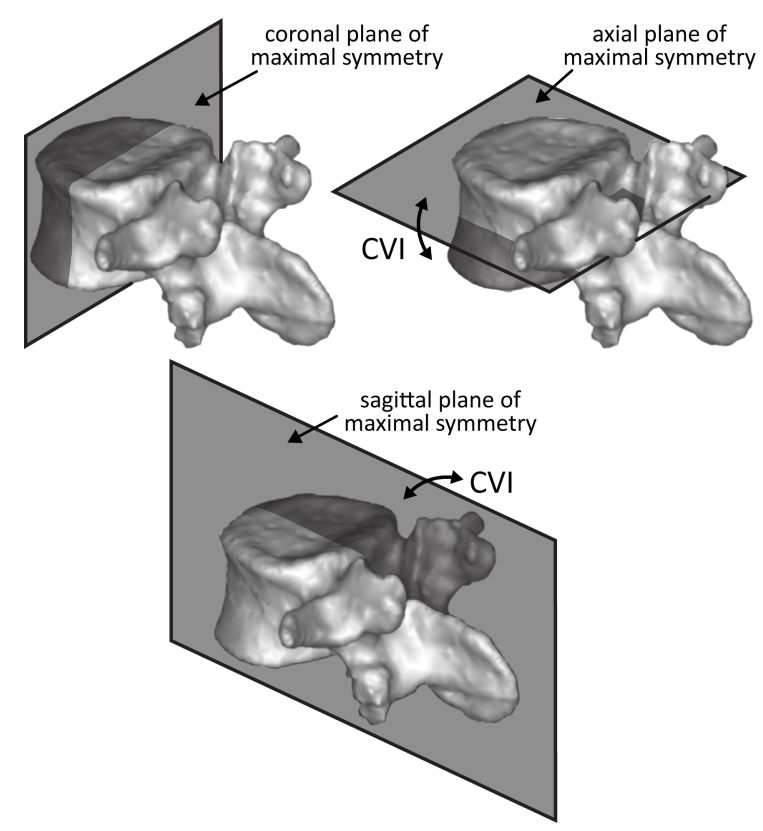

Fig. 2. The planes of maximal symmetry of vertebral anatomical structures and their relation to coronal vertebral inclination $(\mathrm{CVI})$.

\section{COMPUTERIZED CVI MEASUREMENTS}

The computerized measurements were based on a method that determines the sagittal, coronal and axial angle of vertebral rotation in 3D images from the inclination of the planes of maximal symmetry (Vrtovec et al., 2008), which divide the vertebral body into symmetrical left and right, anterior and posterior, and cephalic and caudal halves (Fig. 2). The planes of symmetry are manually initialized so that they are parallel to the axes of the CT image, centered in the vertebral centroid in 3D that represents the center of rotation, and $50 \mathrm{~mm}$ in size to encompass the whole thoracic or lumbar vertebral body. By rotating these planes in $3 \mathrm{D}$, the symmetry of vertebral anatomical structures is automatically evaluated for each combination of the three rotation angles by mirroring the edges of anatomical structures (i.e., image intensity gradients) over each plane and comparing them to the corresponding edges on the other side of that plane. Due to the anatomical 


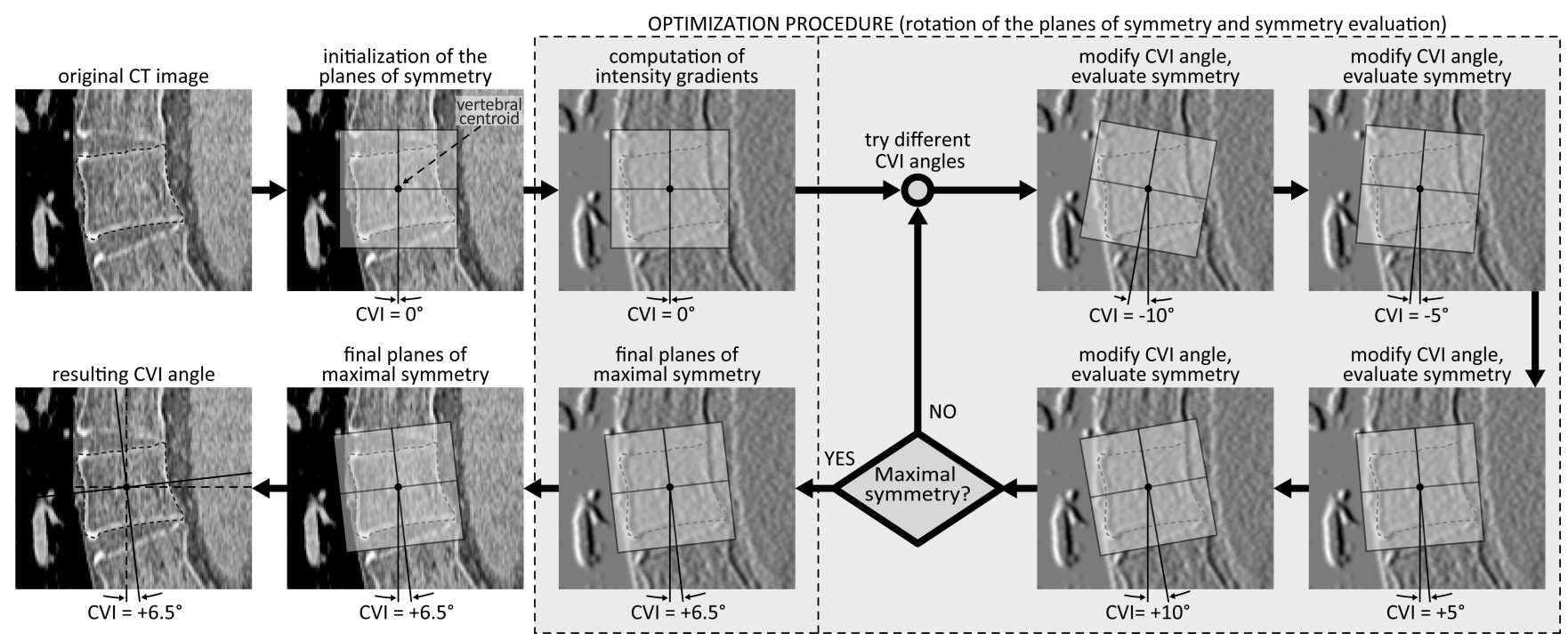

Fig. 3. Computerized measurement of coronal vertebral inclination (CVI) in $2 D$, shown for the T9 scoliotic vertebra, is performed by evaluating the symmetry in the left and right, and in the cephalic and caudal parts of the vertebral body.

characteristics and deformations of vertebral bodies (e.g., wedging), the symmetry of vertebral structures may not be perfect. However, an optimization procedure is applied to search for the planes of maximal available symmetry that define the final rotation angles. By performing measurements in $2 D$, CVI was automatically determined in the same oblique 2D coronal cross-sections that were used for manual measurements (Fig. 3). By performing measurements in $3 D$, the sagittal, coronal and axial angle of rotation were simultaneously determined in 3D images, with the coronal angle of rotation representing CVI (Fig. 4). The average time required to perform computerized measurements for one vertebra was estimated to around $2 \mathrm{~s}$ for measurements in $2 \mathrm{D}$ and around 2.5 min for measurements in 3D (performed on a standard personal computer without code optimization or parallelization and without graphics processing unit acceleration).

\section{STATISTICAL ANALYSIS}

For each of the 28 vertebrae, CVI was determined manually 36 times $(3$ observers $\times 2$ sets $\times$ 6 manual measurements) and automatically 12 times $(3$ observers $\times 2$ initializations $\times 2$ computerized measurements). Statistical analysis was performed in terms of intra-observer variability (observer reproducibility), inter-observer variability (observer reliability) and inter-method variability (measurement agreement), described by standard deviations (SD), intraclass correlation coefficients (ICC) and mean absolute differences (MAD) of the resulting CVI angles. Paired samples $t$-tests were used to search for statistically significant differences in the obtained results (level of significance $\alpha=0.05$, which was subjected to the Bonferroni correction where necessary).

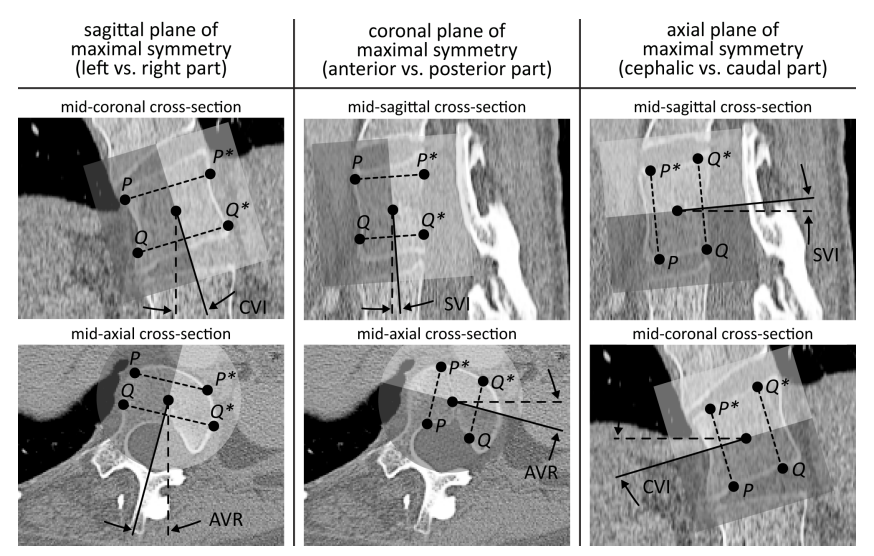

Fig. 4. The sagittal, coronal and axial planes of symmetry are used to determine the coronal inclination $(C V I)$, sagittal inclination (SVI) and axial rotation (AVR) for the L1 scoliotic vertebra in $3 D$ by comparing the points (e.g., $P$ and $Q$ ) on one side of each plane to the corresponding (mirror) points (e.g., $P^{*}$ and $\left.Q^{*}\right)$ on the other side of that plane.

\section{RESULTS}

Fig. 5 shows the mean CVI for each vertebra according to each measurement. For the normal 
vertebrae, the results follow the spinal curvature of a normal spine, which is approximately a straight line. For the scoliotic vertebrae, the results show a right thoracic curve (represented by negative angles) followed by a compensating left thoracolumbar curve (represented by positive angles).

\section{INTRA-OBSERVER VARIABILITY}

Table 1 shows the intra-observer variability for each observer and for each measurement. The average intra-observer variability for observers 1,2 and 3 was $1.1^{\circ}, 1.0^{\circ}$ and $1.5^{\circ} \mathrm{SD}(0.988,0.992$ and 0.979 ICC), respectively, for manual measurements, and $0.8^{\circ}, 0.9^{\circ}$ and $1.1^{\circ} \mathrm{SD}(0.995,0.993$ and 0.987 ICC $)$, respectively, for computerized measurements. The average reproducibility was therefore estimated to $1.2^{\circ}$ $\mathrm{SD}(0.986 \mathrm{ICC})$ for manual measurements and $0.9^{\circ} \mathrm{SD}$ (0.992 ICC) for computerized measurements (average statistical power of 0.73 for the $95 \%$ confidence interval). No statistically significant differences in measurements were found within any observer $(p \geq 0.05)$.

\section{INTER-OBSERVER VARIABILITY}

Table 2 shows the inter-observer variability for each pair of observers and for each measurement. The average inter-observer variability for observer pairs $1 / 2,1 / 3$ and $2 / 3$ was $1.6^{\circ}, 2.0^{\circ}$ and $1.9^{\circ}$ SD $(0.994,0.990$ and 0.991 ICC), respectively, for manual measurements, and $1.2^{\circ}, 1.3^{\circ}$ and $1.4^{\circ}$ SD (0.996, 0.996 and 0.996 ICC), respectively, for computerized measurements. The average reliability was therefore estimated to $1.9^{\circ} \mathrm{SD}(0.992$ ICC) for manual measurements and $1.2^{\circ} \mathrm{SD}(0.996$ ICC) for computerized measurements (average statistical power of 0.77 for the $95 \%$ confidence interval). No statistically significant differences in measurements were found between any observer pair $(p \geq 0.05)$.

\section{INTER-METHOD VARIABILITY AND DIFFERENCE}

The analysis of inter-method variability (SD) and inter-method difference (MAD) is presented in Table 3 for each measurement pair (average statistical power of 0.82 for the $95 \%$ confidence interval). Statistically significant differences were found between the superior tangents and left tangents $(p<0.03)$ or right tangents $(p<0.04)$, between the inferior tangents and left tangents $(p<0.04)$ or right tangents $(p<0.05)$, between the left tangents and every other method $(p<0.04)$, and between the right tangents and every other method $(p<0.05)$. However, by applying the Bonferroni correction, statistically significant differences were found only between the left tangents and right tangents, mid-wall lines or computerized measurements in $2 \mathrm{D}$ and in $3 \mathrm{D}$ $(p<0.002)$, and between the right tangents and midwall lines or computerized measurements in $2 \mathrm{D}$ and in $3 \mathrm{D}(p<0.002)$.

\section{DISCUSSION}

Several methods for assessing the degree of spinal deformities in the coronal plane were developed, such as the Ferguson method (Ferguson, 1930), Cobb method (Cobb, 1948) and centroid method (Chen et al., 2007). As the Cobb angle represents the standard method for radiographic quantification of scoliotic deformities, a number of studies examined its variability. Traditional manual measurements are performed by drawing lines on antero-posterior (AP) or postero-anterior (PA) radiographs. Such measurements are biased by the selection of the most tilted endplates, errors in drawing lines and systematic errors of inaccurate measuring devices (Capasso et al., 1992). As a result, the reported intra-observer SD between $1.5^{\circ}$ and $8.5^{\circ}$, and inter-observer SD between $2.5^{\circ}$ and $8.8^{\circ}$ (Chen et al., 2007; Jeffries et al., 1980; Oda et al., 1982; Goldberg et al., 1988; Dutton et al., 1989; Ylikoski and Tallroth, 1990; Carman et al., 1990; Pruijs et al., 1994; Loder et al., 1995; Diab et al., 1995; Shea et al., 1998; Facanha-Filho et al., 2001; Loder et al., 2004; Wills et al., 2007; Gstoettner et al., 2007; De Carvalho et al., 2007; Tanure et al., 2010) span across a relatively large range of values. Adam et al. (2005) evaluated the Cobb angle in CT images by extracting reformatted cross-sections, resulting in intra- and inter-observer variability of $3.4^{\circ}$ and $2.7^{\circ} \mathrm{SD}$, respectively. Computer-assisted measurements, performed by manually drawing lines on digital radiographs using a computer, improved the reproducibility and reliability of Cobb angle measurements, as studies reported SD between $1.3^{\circ}$ and $4.6^{\circ}$ for intra-observer, and between $1.6^{\circ}$ and $3.2^{\circ}$ for inter-observer variability (Jeffries et al., 1980; Dutton et al., 1989; Shea et al., 1998; Wills et al., 2007; Gstoettner et al., 2007; Tanure et al., 2010; Mok et al., 2008). Chockalingam et al. (2002) performed computer-assisted measurements by constructing the spinal midline from several points that were manually identified on the left and right vertebral body walls. The reported intra- and inter-observer variability in terms of technical error of measurement (TEM) were $0.74^{\circ}$ and $1.22^{\circ}$ (0.985 and 0.988 ICC), which according to the equations presented by the authors result in relatively large SD of $6.0^{\circ}$ and $11.1^{\circ} \mathrm{SD}$, respectively. On the other hand, the computer-assisted 
Table 1. Intra-observer variability for observers 1, 2 and 3, reported as standard deviations (SD) and intraclass correlation coefficients (ICC).

\begin{tabular}{|c|c|c|c|c|c|c|c|c|c|}
\hline \multirow{2}{*}{ Measurement } & \multirow{2}{*}{ Vertebrae } & \multicolumn{4}{|c|}{ Intra-observer SD $\left(^{\circ}\right)$} & \multicolumn{4}{|c|}{ Intra-observer ICC } \\
\hline & & 1 & 2 & 3 & mean & 1 & 2 & 3 & mean \\
\hline \multirow{3}{*}{ superior tangents } & normal & 1.0 & 0.6 & 0.9 & 0.9 & 0.888 & 0.958 & 0.857 & 0.901 \\
\hline & scoliotic & 0.5 & 1.0 & 1.4 & 1.0 & 0.999 & 0.998 & 0.996 & 0.998 \\
\hline & both & 0.8 & 0.8 & 1.2 & 1.0 & 0.998 & 0.997 & 0.994 & 0.996 \\
\hline \multirow{3}{*}{ inferior tangents } & normal & 0.7 & 0.7 & 0.9 & 0.8 & 0.958 & 0.959 & 0.914 & 0.944 \\
\hline & scoliotic & 0.9 & 1.1 & 1.5 & 1.2 & 0.998 & 0.998 & 0.996 & 0.997 \\
\hline & both & 0.8 & 0.9 & 1.2 & 1.0 & 0.997 & 0.997 & 0.994 & 0.996 \\
\hline \multirow{3}{*}{ left tangents } & normal & 1.7 & 0.8 & 1.3 & 1.3 & 0.693 & 0.939 & 0.810 & 0.814 \\
\hline & scoliotic & 1.3 & 1.4 & 2.4 & 1.8 & 0.988 & 0.989 & 0.962 & 0.978 \\
\hline & both & 1.5 & 1.1 & 1.9 & 1.5 & 0.971 & 0.986 & 0.954 & 0.970 \\
\hline \multirow{3}{*}{ right tangents } & normal & 1.0 & 1.2 & 2.0 & 1.5 & 0.951 & 0.929 & 0.892 & 0.924 \\
\hline & scoliotic & 1.9 & 1.5 & 2.2 & 1.9 & 0.981 & 0.988 & 0.970 & 0.978 \\
\hline & both & 1.5 & 1.4 & 2.1 & 1.7 & 0.979 & 0.981 & 0.956 & 0.972 \\
\hline \multirow{3}{*}{ mid-endplate lines } & normal & 0.7 & 0.6 & 0.6 & 0.6 & 0.947 & 0.964 & 0.938 & 0.950 \\
\hline & scoliotic & 0.5 & 0.8 & 1.2 & 0.9 & 0.999 & 0.999 & 0.997 & 0.998 \\
\hline & both & 0.6 & 0.7 & 0.9 & 0.7 & 0.999 & 0.998 & 0.997 & 0.998 \\
\hline \multirow{3}{*}{ mid-wall lines } & normal & 1.0 & 0.9 & 1.0 & 1.0 & 0.833 & 0.863 & 0.888 & 0.861 \\
\hline & scoliotic & 1.2 & 0.9 & 1.5 & 1.2 & 0.991 & 0.995 & 0.984 & 0.990 \\
\hline & both & 1.1 & 0.9 & 1.3 & 1.1 & 0.985 & 0.990 & 0.978 & 0.984 \\
\hline \multirow{3}{*}{ computerized (2D) } & normal & 1.1 & 0.9 & 1.6 & 1.2 & 0.865 & 0.921 & 0.750 & 0.845 \\
\hline & scoliotic & 0.8 & 1.3 & 1.5 & 1.2 & 0.997 & 0.992 & 0.988 & 0.992 \\
\hline & both & 1.0 & 1.1 & 1.5 & 1.2 & 0.991 & 0.989 & 0.977 & 0.986 \\
\hline \multirow{3}{*}{ computerized (3D) } & normal & 0.5 & 0.5 & 0.4 & 0.5 & 0.966 & 0.966 & 0.980 & 0.971 \\
\hline & scoliotic & 0.3 & 0.5 & 0.5 & 0.4 & 0.999 & 0.999 & 0.998 & 0.999 \\
\hline & both & 0.4 & 0.5 & 0.5 & 0.5 & 0.998 & 0.997 & 0.997 & 0.997 \\
\hline
\end{tabular}

measurements based on the identification of vertebral body corners resulted in intra-observer SD between $1.6^{\circ}$ and $2.3^{\circ}$, and inter-observer SD between $2.6^{\circ}$ and $3.2^{\circ}$ (Tanure et al., 2010; Cheung et al., 2002; Stokes and Aronsson, 2006). Further reduction of manual observer interaction was made possible by (semi)automated computerized measurements, which incorporate image processing and analysis techniques into the Cobb angle measurements. Allen et al. (2008) developed a method based on active shape models and reported TEM for intra- and inter-observer variability of $2.0^{\circ}$ and (0.930 and 0.940 ICC), which correspond to relatively large $\mathrm{SD}$ of $8.1^{\circ}$ and $8.4^{\circ}$, respectively. The measurements of Zhang et al. (2010) were based on finding the inclination of the edges obtained by the Hough transform. The authors reported intra-observer SD of $1.2^{\circ}$ (ICC between 0.916 and 0.994) and inter- observer SD between $1.8^{\circ}$ and $2.1^{\circ}$ (ICC between 0.908 and 0.985). Chen et al. (2007) performed manual measurements by a different method that was based on the identification of vertebral centroids and reported intra- and inter-observer variability of $2.2^{\circ}$ and $2.6^{\circ} \mathrm{SD}$, respectively. In a recent evaluation of manual and computerized measurement of CVI in magnetic resonance (MR) images (Vrtovec et al., 2013), the mid-endplate lines proved to be the most reproducible $\left(1.0^{\circ} \mathrm{SD}\right)$ and reliable $\left(1.4^{\circ} \mathrm{SD}\right)$ manual measurements, while the computerized measurements in $3 \mathrm{D}$ yielded lower intra-observer $\left(0.8^{\circ} \mathrm{SD}\right)$ and interobserver $\left(1.3^{\circ} \mathrm{SD}\right)$ variability. The strongest intermethod agreement $\left(1.2^{\circ} \mathrm{SD}\right.$ and $\left.0.4^{\circ} \mathrm{MAD}\right)$ was found among lines parallel to vertebral endplates, however, the computerized measurements in 3D were most in agreement with the mid-endplate lines $\left(1.9^{\circ} \mathrm{SD}\right.$ and 
Table 2. Inter-observer variability for observer pairs $1 / 2,1 / 3$ and 2/3, reported as standard deviations (SD) and intraclass correlation coefficients (ICC).

\begin{tabular}{|c|c|c|c|c|c|c|c|c|c|}
\hline \multirow{2}{*}{ Measurement } & \multirow{2}{*}{ Vertebrae } & \multicolumn{4}{|c|}{ Inter-observer SD $\left(^{\circ}\right)$} & \multicolumn{4}{|c|}{ Inter-observer ICC } \\
\hline & & $1 / 2$ & $1 / 3$ & $2 / 3$ & mean & $1 / 2$ & $1 / 3$ & $2 / 3$ & mean \\
\hline \multirow{3}{*}{ superior tangents } & normal & 1.3 & 1.3 & 1.4 & 1.3 & 0.912 & 0.947 & 0.876 & 0.912 \\
\hline & scoliotic & 1.6 & 1.9 & 2.0 & 1.8 & 0.998 & 0.998 & 0.997 & 0.998 \\
\hline & both & 1.6 & 1.6 & 1.8 & 1.7 & 0.996 & 0.997 & 0.995 & 0.996 \\
\hline \multirow{3}{*}{ inferior tangents } & normal & 1.0 & 1.6 & 1.4 & 1.4 & 0.980 & 0.914 & 0.938 & 0.944 \\
\hline & scoliotic & 1.3 & 1.5 & 1.6 & 1.5 & 0.999 & 0.998 & 0.999 & 0.999 \\
\hline & both & 1.3 & 1.6 & 1.5 & 1.5 & 0.998 & 0.996 & 0.998 & 0.997 \\
\hline \multirow{3}{*}{ left tangents } & normal & 1.7 & 2.1 & 1.7 & 1.8 & 0.936 & 0.862 & 0.871 & 0.890 \\
\hline & scoliotic & 2.0 & 2.2 & 2.4 & 2.2 & 0.990 & 0.995 & 0.993 & 0.993 \\
\hline & both & 1.9 & 2.2 & 2.1 & 2.1 & 0.988 & 0.988 & 0.986 & 0.987 \\
\hline \multirow{3}{*}{ right tangents } & normal & 1.9 & 2.9 & 2.7 & 2.5 & 0.949 & 0.895 & 0.923 & 0.922 \\
\hline & scoliotic & 2.3 & 3.0 & 2.8 & 2.7 & 0.993 & 0.984 & 0.988 & 0.988 \\
\hline & both & 2.1 & 2.9 & 2.7 & 2.6 & 0.989 & 0.972 & 0.979 & 0.980 \\
\hline \multirow{3}{*}{ mid-endplate lines } & normal & 0.9 & 1.1 & 1.2 & 1.1 & 0.972 & 0.945 & 0.922 & 0.946 \\
\hline & scoliotic & 1.2 & 1.3 & 1.4 & 1.3 & 0.999 & 0.999 & 0.999 & 0.999 \\
\hline & both & 1.2 & 1.3 & 1.3 & 1.2 & 0.998 & 0.998 & 0.998 & 0.998 \\
\hline \multirow{3}{*}{ mid-wall lines } & normal & 1.2 & 1.6 & 1.5 & 1.4 & 0.965 & 0.880 & 0.907 & 0.917 \\
\hline & scoliotic & 1.5 & 1.8 & 1.8 & 1.7 & 0.997 & 0.996 & 0.994 & 0.996 \\
\hline & both & 1.3 & 1.7 & 1.7 & 1.6 & 0.996 & 0.990 & 0.990 & 0.992 \\
\hline \multirow{3}{*}{ computerized (2D) } & normal & 1.5 & 1.6 & 1.8 & 1.6 & 0.935 & 0.962 & 0.916 & 0.938 \\
\hline & scoliotic & 1.6 & 1.7 & 1.9 & 1.7 & 0.996 & 0.997 & 0.995 & 0.996 \\
\hline & both & 1.5 & 1.6 & 1.8 & 1.6 & 0.994 & 0.995 & 0.992 & 0.994 \\
\hline \multirow{3}{*}{ computerized (3D) } & normal & 0.7 & 0.8 & 0.8 & 0.8 & 0.980 & 0.972 & 0.981 & 0.978 \\
\hline & scoliotic & 0.6 & 0.8 & 0.6 & 0.7 & 0.999 & 0.999 & 0.999 & 0.999 \\
\hline & both & 0.7 & 0.8 & 0.7 & 0.7 & 0.998 & 0.997 & 0.999 & 0.998 \\
\hline
\end{tabular}

$1.1^{\circ}$ MAD). The results obtained in the current study are, in terms of intra- and inter-observer variability, comparable to the above mentioned findings. Although none of these studies was focused on segmental measurements, the angle between arbitrary two vertebral levels can be obtained from the segmental angles, e.g. the difference between the angles of the superior and inferior tangents at two selected vertebrae results in the classical Cobb angle measurement. If the mean measured angles for the T12 and T5 vertebral level are subtracted, $\left(-2.4^{\circ}-\left(-5.2^{\circ}\right)\right)=$ $2.8^{\circ}$ is obtained for the normal and $\left(+37.2^{\circ}-\right.$ $\left.\left(-25.4^{\circ}\right)\right)=62.6^{\circ}$ is obtained for the scoliotic spine, which approximately correspond to the diagnosed Cobb angles of $1^{\circ}$ and $60^{\circ}$, respectively. However, to compare the variability of our measurements to the classical Cobb angle measurements, the variabilities of both superior and inferior tangents have to be considered. The resulting intra-observer variability of $\sqrt{1.0^{2}+1.0^{2}}=1.4^{\circ} \mathrm{SD}$ and inter-observer variability of $\sqrt{1.7^{2}+1.5^{2}}=2.3^{\circ} \mathrm{SD}$ are lower than the values reported by studies that performed computer-assisted Cobb angle measurements based on the identification of vertebral body corners. This may result from the fact that in radiographs, the vertebral body corners are more difficult to identify than in CT cross-sections due to the occlusion of anatomical structures and projective nature of radiographic imaging. In comparison to MR images (Vrtovec et al., 2013), the lower variability of measurements in CT images obtained in the current study points to the fact that the edges of bone structures can be extracted more accurately from CT than from MR images. Nevertheless, most of the above mentioned studies were focused on evaluating the 
Table 3. Inter-method variability (lower-left triangle in normal text), reported as standard deviations (SD) of measurements, and inter-method difference (upper-right triangle in bold text), reported as mean absolute differences (MAD) of measurements.

\begin{tabular}{|c|c|c|c|c|c|c|c|c|}
\hline & 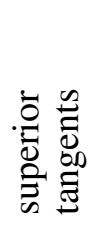 & 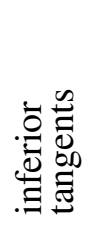 & 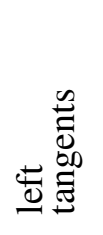 & 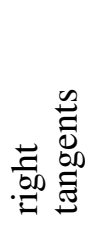 & 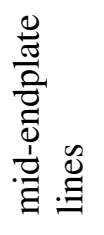 & 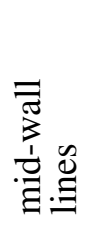 & 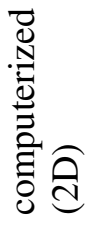 & 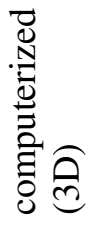 \\
\hline & \multicolumn{8}{|c|}{ Normal vertebrae: $\operatorname{SD}\left({ }^{\circ}\right)$, MAD $\left(^{\circ}\right)$} \\
\hline superior tangents & $*$ & 1.5 & 3.6 & 5.2 & 0.8 & 1.3 & 1.3 & 1.7 \\
\hline inferior tangents & 2.3 & $*$ & 4.1 & 5.2 & 0.7 & 1.6 & 1.9 & 2.2 \\
\hline left tangents & 3.6 & 3.4 & * & 8.5 & 3.8 & 4.3 & 4.7 & 4.7 \\
\hline right tangents & 3.8 & 4.4 & 6.5 & * & 5.1 & 4.3 & 4.1 & 4.0 \\
\hline mid-endplate lines & 1.4 & 1.3 & 3.3 & 3.9 & $*$ & 1.4 & 1.6 & 2.0 \\
\hline mid-wall lines & 1.7 & 2.3 & 3.4 & 3.4 & 1.6 & $*$ & 1.0 & 1.6 \\
\hline computerized (2D) & 2.2 & 2.7 & 3.7 & 3.7 & 2.2 & 1.8 & $*$ & 1.4 \\
\hline \multirow[t]{2}{*}{ computerized (3D) } & 2.3 & 2.9 & 3.8 & 4.1 & 2.4 & 2.2 & 2.2 & $*$ \\
\hline & \multicolumn{8}{|c|}{ Scoliotic vertebrae: $\operatorname{SD}\left({ }^{\circ}\right)$, MAD $\left(^{\circ}\right)$} \\
\hline superior tangents & $*$ & 3.3 & 8.8 & 8.4 & 1.7 & 8.1 & 6.8 & 8.2 \\
\hline inferior tangents & 4.7 & $*$ & 9.0 & 8.7 & 1.6 & 8.5 & 7.5 & 8.7 \\
\hline left tangents & 10.6 & 11.1 & $*$ & 4.9 & 8.7 & 2.5 & 2.6 & 2.2 \\
\hline right tangents & 9.7 & 10.3 & 4.2 & $*$ & 8.1 & 2.5 & 2.9 & 2.7 \\
\hline mid-endplate lines & 2.6 & 2.5 & 10.7 & 9.8 & $*$ & 8.0 & 6.8 & 8.1 \\
\hline mid-wall lines & 10.0 & 10.6 & 2.3 & 2.5 & 10.1 & * & 1.7 & 1.2 \\
\hline computerized (2D) & 8.4 & 9.3 & 3.5 & 3.1 & 8.6 & 2.5 & * & 1.5 \\
\hline \multirow[t]{2}{*}{ computerized (3D) } & 9.9 & 10.8 & 2.7 & 3.0 & 10.2 & 1.8 & 2.1 & $*$ \\
\hline & \multicolumn{8}{|c|}{ Normal and scoliotic vertebrae: SD $\left(^{\circ}\right)$, MAD $\left(^{\circ}\right)$} \\
\hline superior tangents & $*$ & 2.4 & 6.2 & 6.8 & 1.2 & 4.7 & 4.0 & $\mathbf{5 . 0}$ \\
\hline inferior tangents & 3.7 & * & 6.5 & $\mathbf{7 . 0}$ & 1.1 & 5.0 & 4.7 & 5.5 \\
\hline left tangents & 7.8 & 8.1 & * & 6.7 & 6.3 & 3.4 & 3.6 & 3.5 \\
\hline right tangents & 7.6 & 8.0 & 5.8 & $*$ & 6.6 & 3.4 & 3.5 & 3.4 \\
\hline mid-endplate lines & 2.1 & 2.0 & 7.8 & 7.6 & $*$ & 4.7 & 4.2 & 5.0 \\
\hline mid-wall lines & 7.1 & 7.6 & 3.1 & 3.2 & 7.1 & $*$ & 1.3 & 1.4 \\
\hline computerized (2D) & 6.1 & 6.8 & 3.7 & 3.5 & 6.2 & 2.2 & $*$ & 1.5 \\
\hline computerized (3D) & 7.2 & 7.8 & 3.6 & 3.6 & 7.3 & 2.0 & 2.1 & $*$ \\
\hline
\end{tabular}

variability of one type of measurements and did not address the variability among different measurements, i.e., the inter-method variability and/or difference of CVI measurements in CT images, which was besides intra-observer and inter-observer variabilities analyzed in the current study.

\section{MANUAL CVI MEASUREMENTS}

The mid-endplate lines proved to be the most reproducible $\left(0.7^{\circ} \mathrm{SD}, 0.998 \mathrm{ICC}\right)$ and reliable $\left(1.2^{\circ}\right.$ SD, 0.998 ICC) manual measurements (Tables 1 and 2). The superior and inferior tangents were less reproducible $\left(1.0^{\circ}\right.$ and $1.0^{\circ} \mathrm{SD}, 0.996$ and 0.996 ICC, respectively) and reliable $\left(1.7^{\circ}\right.$ and $1.5^{\circ} \mathrm{SD}$, 0.996 and 0.997 ICC, respectively), while the left and right tangents were the least reproducible $\left(1.5^{\circ}\right.$ and $1.7^{\circ} \mathrm{SD}, 0.970$ and $0.972 \mathrm{ICC}$, respectively) and reliable $\left(2.1^{\circ}\right.$ and $2.6^{\circ} \mathrm{SD}, 0.978$ and $0.980 \mathrm{ICC}$, respectively) manual measurements. Such results were expected, since the left and right vertebral body walls are subjected to vertebral body wedging, which is especially strong in the case of scoliosis, and therefore may not represent the correct CVI. This is also reflected in poor agreement between the left tangents, right tangents and mid-wall lines (Table 3). The mid- 


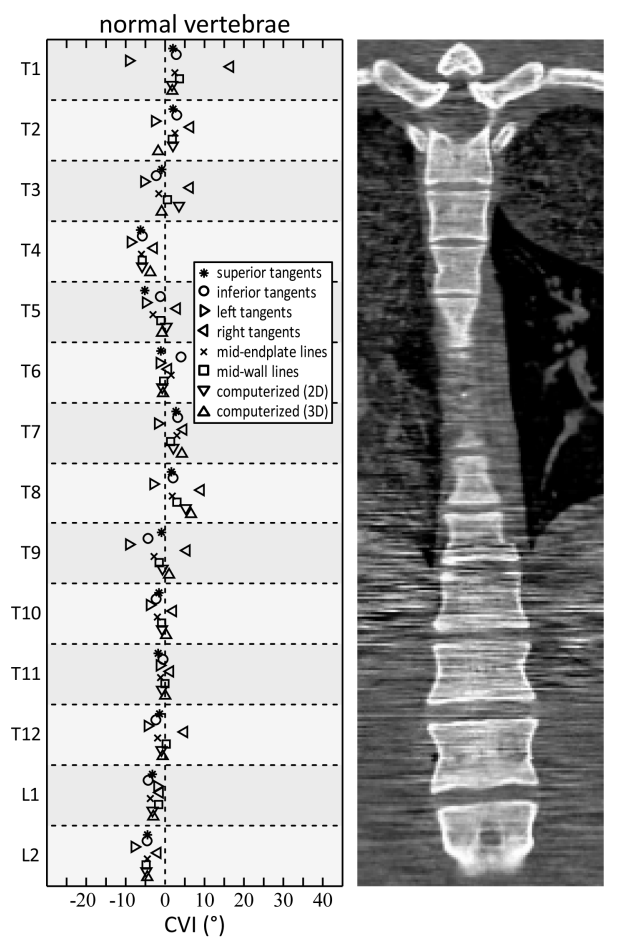

(a)

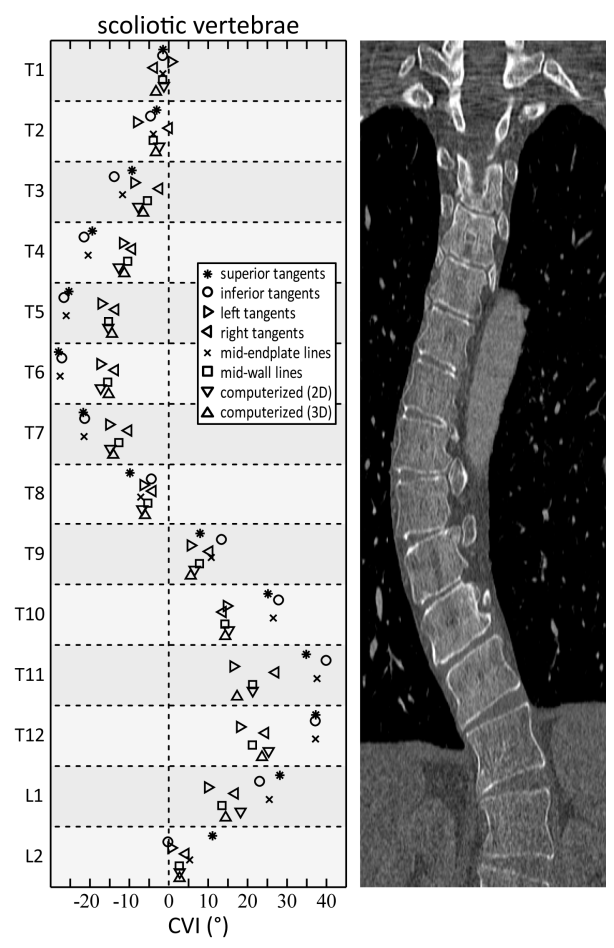

(b)

Fig. 5. Mean coronal vertebral inclination (CVI) for each vertebral level and for each measurement, shown for (a) normal and (b) scoliotic vertebrae with corresponding illustrative cross-sections.

wall lines were, on the other hand, more reproducible $\left(1.1^{\circ} \mathrm{SD}, 0.984 \mathrm{ICC}\right)$ and reliable $\left(1.6^{\circ} \mathrm{SD}, 0.992\right.$ ICC), but were based on the determination of all four vertebral body corners (Fig. 1). The average intraobserver and inter-observer variability of manually localizing the vertebral body corners was $0.5 \mathrm{~mm}$ and $0.6 \mathrm{~mm} \mathrm{SD}$, respectively, which is reflected in the low variability of the measured angles according to the mid-endplate and mid-wall lines.

\section{COMPUTERIZED CVI MEASUREMENTS}

The computerized measurements in $2 \mathrm{D}$ were as reproducible and reliable $\left(1.2^{\circ}\right.$ and $1.6^{\circ} \mathrm{SD}, 0.986$ and 0.994 ICC, respectively), while the computerized measurements in 3D were even more reproducible and reliable $\left(0.5^{\circ}\right.$ and $0.7^{\circ} \mathrm{SD}, 0.997$ and 0.998 ICC, respectively) than the manual measurements (Tables 1 and 2). Such results may originate from the fact that a single anatomical landmark, i.e., the vertebral centroid, was required for each vertebra to measure CVI in 3D. The average intra- and inter-observer variability of manual identification of vertebral centroids in 3D was $0.5 \mathrm{~mm}$ and $0.8 \mathrm{~mm} \mathrm{SD}$, respectively, which can be considered the major source of variability for the computerized CVI measurement since a change of around $1 \mathrm{~mm}$ in the center of rotation reflects in an change of around $2^{\circ}$ in the rotation angle for an object of around $30 \mathrm{~mm}$ in size (e.g. the vertebral body).

\section{COMPARISON OF MEASUREMENTS}

The magnitudes of CVI angles, shown in Fig. 5, were consistent among measurements based on lines that are approximately parallel, i.e., among the superior tangents, inferior tangents and mid-endplate lines, and among the left tangents, right tangents and mid-wall lines. Moreover, there is considerable difference between these two groups, as CVI obtained from lines parallel to vertebral body walls is in magnitude lower than CVI obtained from lines parallel to vertebral body endplates. This indicates that, although there may be significant wedging of the vertebral body, the inclination of vertebral endplates is larger than the inclination of vertebral body walls. The computerized measurements were more consistent with the lines parallel to vertebral body walls, which indicates that the evaluated symmetry of vertebral anatomical structures was stronger between the left and right parts than between the cephalic and caudal parts of the vertebral body. However, the CT image in-plane resolution (between $0.6 \mathrm{~mm}$ and $0.7 \mathrm{~mm}$ ) was lower than the slice thickness $(1 \mathrm{~mm})$, therefore more information for symmetry evaluation could be extracted from edges in the left-to-right 
direction. When compared to the mid-endplate lines, the computerized measurements in $3 \mathrm{D}$ were even more reproducible $\left(0.5^{\circ}\right.$ vs. $\left.0.7^{\circ} \mathrm{SD}\right)$ and reliable $\left(0.7^{\circ}\right.$ vs. $\left.1.2^{\circ} \mathrm{SD}\right)$. In terms of measurement agreement, they were most consistent with the mid-wall lines $\left(2.0^{\circ}\right.$ $\mathrm{SD}$ and $1.4^{\circ} \mathrm{MAD}$ ), which therefore best describe the symmetry of vertebral anatomical structures in the coronal plane. When comparing the intra- and interobserver variability of different CVI measurements for normal and scoliotic vertebrae (Tables 1 and 2), the measurements for normal vertebrae were more reproducible and reliable, however, the differences were relatively small. The measurement agreement (Table 3) was stronger for normal than for scoliotic vertebrae, which was expected as vertebral body deformations increase with scoliosis. The most important advantage of computerized over manual measurements is the reduction of observer interaction. For manual measurements, the observers had to identify the vertebral centroid in 3D, the oblique coronal cross-section, and characteristic points or lines in the extracted oblique cross-section for each observed vertebra. For computerized measurements in $3 \mathrm{D}$, the observers had to initialize only the vertebral centroid in 3D. Computerized measurements were therefore considerably faster and less observerdependent than manual measurements.

\section{CONCLUSION}

Coronal vertebral inclination (CVI) was systematically measured in CT images using six manual and two computerized measurements. The mid-endplate lines proved to be the most reproducible and reliable manual measurements, while the computerized measurements in $3 \mathrm{D}$ were even more reproducible and reliable than the mid-endplate lines. However, the computerized measurements, based on the evaluation of the symmetry of vertebral anatomical structures, were most consistent with manual measurements, based on lines parallel to vertebral body walls. From the clinical perspective, the conclusions drawn from the results are twofold. If performing measurements of CVI from 2D images, it is recommended to use a method that yields the largest amount of geometrical information. In the case of manual measurements, a method based on the identification of all four vertebral body corners is therefore the selection of choice. Among the two methods that rely on all four vertebral body corners, the mid-endplate lines are more reproducible and reliable than the mid-wall lines, probably because they are less affected by vertebral body wedging. Moreover, the mid-endplate lines provide measurements that are most comparable to the Cobb angle measurements, which is the standard method for evaluating spinal deformities in the coronal plane. However, the computerized method in 2D also proved of satisfying measurement reproducibility and reliability, but with a considerable reduction of observer interaction. On the other hand, when measuring CVI from 3D images, the computerized method is the only selection of choice, as manual measurements are not feasible due to the limitation of the observers to accurately interpret the anatomical configuration in $3 \mathrm{D}$, while the computerized method is able to take full advantage of the available 3D image information. From the technical perspective, it is therefore essential to develop techniques that will extract proper image information and correlate it with geometrical information that defines vertebral rotation.

\section{ACKNOWLEDGEMENTS}

This work has been supported by the Slovenian Research Agency under grants P2-0232, J7-2264, L27381, and L2-2023. The authors thank R. Vengust (University Medical Centre Ljubljana, Department of Orthopedic Surgery, Slovenia) and D. Štern (University of Ljubljana, Faculty of Electrical Engineering, Slovenia; currently with the Institute for Computer Graphics and Vision, Graz University of Technology, Austria) for performing manual measurements. The CT spine images were provided by the University Medical Center Utrecht, the Netherlands.

\section{REFERENCES}

Adam CJ, Izatt MT, Harvey JR, Askin GN (2005). Variability in Cobb angle measurements using reformatted computerized tomography scans. Spine 30:1664-9.

Allen S, Parent E, Khorasani M, Hill DL, Lou E, Raso JV (2008). Validity and reliability of active shape models for the estimation of Cobb angle in patients with adolescent idiopathic scoliosis. J Digit Imaging 21:20818.

Capasso G, Maffulli N, Testa V (1992). The validity and reliability of measurements in spinal deformities: a critical appraisal. Acta Orthop Belg 58:126-35.

Carman DL, Browne RH, Birch JG (1990). Measurement of scoliosis and kyphosis radiographs: intraobserver and interobserver variation. J Bone Joint Surg Am 72:32833.

Chen Y-L, Chen W-J, Chiou W-K (2007). An alternative method for measuring scoliosis curvature. Orthopedics 30:828-31. 
Cheung J, Wever DJ, Veldhuizen AG, Klein JP, Verdonck B, Nijlunsing R, et al. (2002). The reliability of quantitative analysis on digital images of the scoliotic spine. Eur Spine J 11:535-42.

Chockalingam N, Dangerfield PH, Giakas G, Cochrane T, Dorgan JC (2002). Computer-assisted Cobb measurement of scoliosis. Eur Spine J 11:353-7.

Cobb JR (1948). Outline for the study of scoliosis. Am Acad Orthop Surg Instr Course Lect 5:261-75.

De Carvalho A, Vialle R, Thomsen L, Amzallag J, Cluzel G, Pointe H, Mary P (2007). Reliability analysis for manual measurement of coronal plane deformity in adolescent scoliosis. Are $30 \times 90 \mathrm{~cm}$ plain films better than digitized small films? Eur Spine J 16:1615-20.

Diab KM, Sevastik JA, Hedlund R, Suliman IA (1995). Accuracy and applicability of measurement of the scoliotic angle at the frontal plane by Cobb's method, by Ferguson's method and by a new method. Eur Spine J 4:291-5.

Dutton KE, Jones TJ, Slinger BS, Scull ER, O'Connor J (1989). Reliability of the Cobb angle index derived by traditional and computer assisted methods. Australas Phys Eng Sci Med 12:16-23.

Facanha-Filho FA, Winter RB, Lonstein JE, Koop S, Novacheck T, L'Heureux EA, et al. (2001). Measurement accuracy in congenital scoliosis. J Bone Joint Surg Am 83:42-5.

Ferguson AB (1930). The study and treatment of scoliosis. South Med J 23:116-20.

Goldberg MS, Poitras B, Mayo NE, Labelle H, Bourassa $\mathrm{R}$, Cloutier R (1988). Observer variation in assessing spinal curvature and skeletal development in adolescent idiopathic scoliosis. Spine 13:1371-7.

Gstoettner M, Sekyra K, Walochnik N, Winter P, Wachter $\mathrm{R}$, Bach CM (2007). Inter- and intraobserver reliability assessment of the Cobb angle: manual versus digital measurement tools. Eur Spine J 16:1587-92.

Jeffries BF, Tarlton M, De Smet AA, Dwyer SJ, Brower AC (1980). Computerized measurement and analysis of scoliosis: a more accurate representation of the shape of the curve. Radiology 134:381-5.

Loder RT, Urquhart A, Steen H, Graziano G, Hensinger RN, Schlesinger A, et al. (1995). Variability in Cobb angle measurements in children with congenital scoliosis. J Bone Joint Surg Br 77:768-70.

Loder RT, Spiegel D, Gutknecht S, Kleist K, Ly T,
Mehbod A (2004). The assessment of intraobserver and interobserver error in the measurement of noncongenital scoliosis in children less or equal 10 years of age. Spine 29:2548-53.

Mok JM, Berven SH, Diab M, Hackbarth M, Hu SS, Deviren V (2008). Comparison of observer variation in conventional and three digital radiographic methods used in the evaluation of patients with adolescent idiopathic scoliosis. Spine 33:681-6.

Oda M, Rauh S, Gregory PB, Silverman FN, Bleck $\mathrm{EE}$ (1982). The significance of roentgenographic measurement in scoliosis. J Pediatr Orthop 2:378-82.

Pruijs JE, Hageman MA, Keessen W, van der Meer R, van Wieringen JC (1994). Variation in Cobb angle measurements in scoliosis. Skeletal Radiol 23:517-20.

Shea KG, Stevens PM, Nelson M, Smith JT, Masters KS, Yandow S (1998). A comparison of manual versus computer-assisted radiographic measurement: intraobserver measurement variability for Cobb angles. Spine 23:551-5.

Stokes IAF, Aronsson DD (2006). Computer-assisted algorithms improve reliability of King classification and Cobb angle measurement of scoliosis. Spine 31:665-70.

Tanure MC, Pinheiro AP, Oliveira AS (2010). Reliability assessment of Cobb angle measurements using manual and digital methods. Spine J 10:769-74.

Vrtovec T, Pernuš F, Likar B (2008). A symmetry-based method for the determination of vertebral rotation in 3D. Lect Notes Comput Sci 5241:942-50.

Vrtovec T, Likar B, Pernuš F (2013). Manual and computerized measurement of coronal vertebral inclination in MRI images: a pilot study. Clin Radiol 68:807-14.

Wills BPD, Auerbach JD, Zhu X, Caird MS, Horn BD, Flynn JM, et al. (2007). Comparison of Cobb angle measurement of scoliosis radiographs with preselected end vertebrae: traditional versus digital acquisition. Spine 32:98-105.

Ylikoski M, Tallroth K (1990). Measurement variations in scoliotic angle, vertebral rotation, vertebral body height, and intervertebral disc space height. J Spinal Disord Tech 3:387-91.

Zhang J, Lou E, Shi X, Wang Y, Hill DL, Raso JV, et al. (2010). A computer-aided Cobb angle measurement method and its reliability. J Spinal Disord Tech 23:3837. 